\title{
NUMERICAL SIMULATION OF SNOWDRIFT DEVELOPMENT
}

\author{
by
}

\author{
T. Uematsu, Y. Kaneda, K. Takeuchi, T. Nakata, and M. Yukumi \\ (Japan Weather Association, Hokkaido, Sapporo 064, Japan)
}

\section{ABSTRACT}

A two-dimensional, finite-element calculation was performed to simulate the development of a snowdrift. The underlying two-dimensional topography was taken as the lower boundary, and this changed as the drift developed. The two-dimensional wind field was calculated from the Navier-Stokes equations. The calculation was performed until a quasi-steady state was reached, and the pattern of erosion and deposition was estimated by computing the divergence of snowdrift transport. Considering a snowdrift as a new surface, the wind field was then recalculated. Simulated results were compared with outdoor observations of the wind field and snowdrifts. The results were in fairly good agreement with each other, but more detailed research is regarded as being necessary.

\section{INTRODUCTION}

Snowdrifts can greatly influence human activities in snowy areas. Many studies of snowdrifts have been carried out over the years with experimental methods employing wind tunnels (Kobayashi, 1972; Anno, 1985) and water tanks (Irwin, 1983). These methods usually require expensive equipment. We are developing a numerical simulation method for snowdrifts which we hope will prove useful in the design of roads and houses in snowy regions. We report here preliminary results of this recently developed method.

When wind speed exceeds a certain critical value, snow particles are entrained and are then transported down-wind. Such transport is possible either by saltation or by suspension. We have assumed that the majority of wind-driven snow particles move by saltation (Kobayashi, 1972), and therefore consider only snow transport caused by this. Wipperman and Gross (1985) have made several attempts to simulate the development of a sand barchan, which has a sickle-shaped form. Sand transport in barchan development is brought about mainly by saltation, so we adopt their procedure in the following three steps:

(a) Calculation of wind field, in order to obtain the friction velocity at each point.

(b) Calculation of distribution of snowdrift transport due to distribution of friction velocity given by (a).

(c) Calculation of the field of erosion and deposition rates by computing the divergence of snow drift transport.

Adding these increments to the initial height of the field leads to the new shape after a time interval. Wipperman and Gross (1985) did not verify their simulation results with field data, but in our work we have been able to compare the simulated wind-velocity field and snowdrifts with those actually observed. We have adopted the finite-element method for calculation of the wind field, but it should be noted that Wipperman and Gross used the finite-difference method. Generally speaking, we can express smooth topographies easily because the finite-element method gives more reasonable answers in the case of complex boundaries than does the finite-difference method. This is very important because wind profiles near boundaries influence snowdrifts.
Figure 1 shows the model topography used. This model is constructed in wood and permits comparison of calculated results with those observed from a snowdrift outdoors. The method was developed by Tabler and others (1980).

\section{SIMULATION OF WIND-VELOCITY FIELD}

The friction velocity, $u *$, was obtained from a velocity profile.

A numerical simulation method developed by Ohnishi (1986) was applied in order to obtain a two-dimensional velocity field over the topography. When the viscous fluid is assumed to be incompressible, the Navier-Stokes equations in the two-dimensional case reduce to

$$
\begin{aligned}
& \frac{\partial u}{\partial t}+u \frac{\partial u}{\partial x}+v \frac{\partial u}{\partial y}=-\frac{1}{\rho} \frac{\partial P}{\partial x}+\left(v_{t}+v\right) \nabla^{2} u \\
& \frac{\partial v}{\partial t}+u \frac{\partial v}{\partial x}+v \frac{\partial v}{\partial y}=-\frac{1}{\rho} \frac{\partial P}{\partial y}+\left(v_{t}+v\right) \nabla^{2} v
\end{aligned}
$$

where $x$ and $y$ are horizontal and vertical coordinates, $u$ and $v$ are horizontal and vertical components of velocity, $v_{t}$ is the eddy diffusivity of momentum and $v$ is the kinematic coefficient of viscosity. In this paper, the eddy diffusivity of momentum was set as the constant: $v_{t}=0.10$.

By differentiating and adding together Equations (1.1) and (1.2), we get

$$
\frac{\partial w}{\partial t}+u \frac{\partial w}{\partial x}+v \frac{\partial w}{\partial y}=v_{t} \nabla^{2} \omega
$$

where

$$
\omega=\frac{\partial v}{\partial x}-\frac{\partial u}{\partial y}
$$

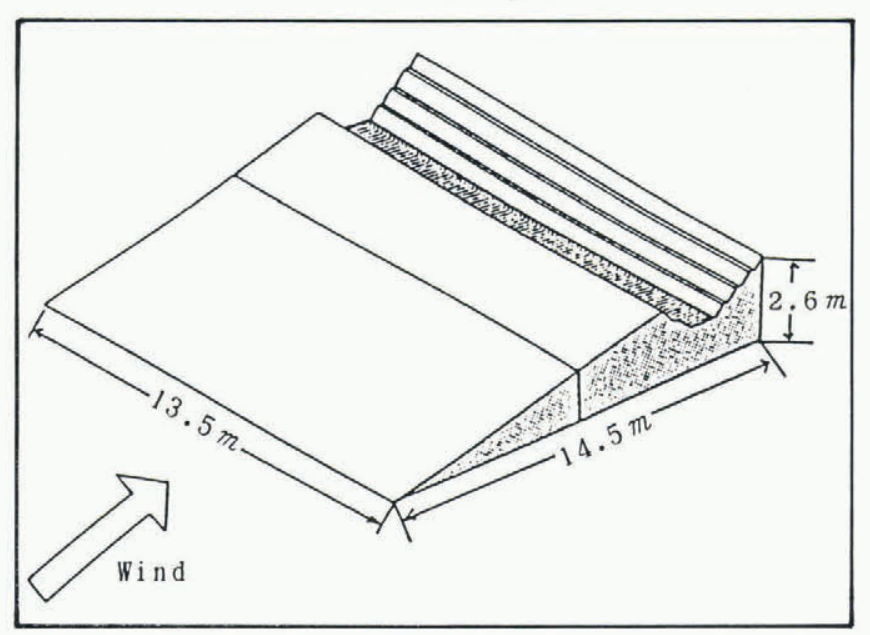

Fig. 1. Schematic diagram showing an outdoor model for a snowdrift. 


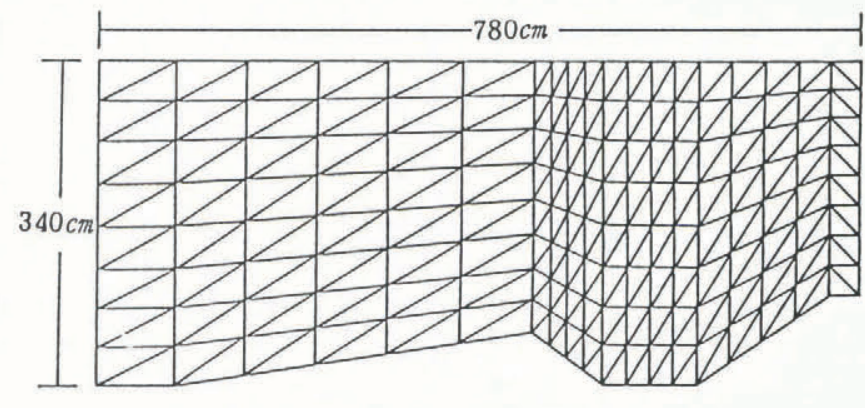

$\omega_{8}=0$

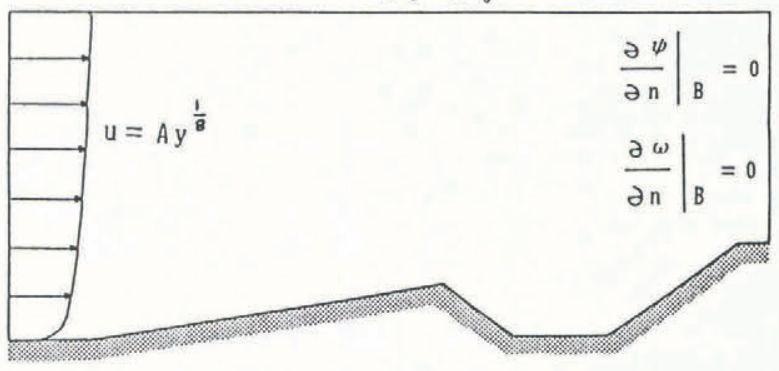

Fig. 2. Characteristics of topography division and air-flow conditions in calculation. Boundary conditions: at the inflow boundary, $u(z)$ is given. At the other lateral boundary, $\quad \partial \psi / \partial n=0$ and $\partial \omega / \partial n=0$. At the upper boundary, $\omega=0$. No-slip conditions apply at the lower boundary.

Since $v_{t}$ is generally much larger than $v, v$ can be ignored. The velocities, $u$ and $v$, are given by a stream function, $\psi$, such that

$u=\frac{\partial \psi}{\partial y}$

$$
v=\frac{\partial \psi}{\partial x}
$$

Substitution of Equations (4.1) and (4.2) into Equation (3) gives

$$
-\omega=\frac{\partial^{2} \psi}{\partial x^{2}}+\frac{\partial^{2} \psi}{\partial y^{2}}
$$

and Equation (2) becomes

$$
\frac{\partial \omega}{\partial t}+\left(\frac{\partial \psi}{\partial y} \cdot \frac{\partial \omega}{\partial x}-\frac{\partial \psi}{\partial x} \cdot \frac{\partial \omega}{\partial y}\right)=v_{t} \nabla^{2} \omega .
$$

Equations (5) and (6) are those used in the simulation.

Figure 2 shows the topography on which the calculation is based and its component elements. This topography is simpler than that actually observed, in that there are no steps on the slopes and no anti-glare screen at the centre of the trench. The wind profile at the inflow boundary velocity is given by the observed wind profile, the other boundary condition is also shown in Figure 2. The simple Euler scheme is used for time integration, the time interval, $\Delta t$, being $200-300 \mathrm{~s}$. The numbers of nodes and elements are 180 and 304 , respectively. The friction velocity is computed from the logarithmic wind profile

$$
u *=\frac{u(z) k}{\ln \left(z / z_{0}\right)}
$$

where $u(z)$ is the wind velocity at level $z ; z$ is the height of the element nearest a surface, $\boldsymbol{k}$ is the von Kármán constant $(=0.4)$, and $z_{0}$ is the roughness length, taken as constant $\left(=3.2 \times 10^{-3} \mathrm{~cm}\right)$.

This means that the wind profile is independent of saltation.

\section{COMPUTATION OF SNOW TRANSPORT}

The snowdrift-transport rate, $q$ (more correctly called the vertically integrated snowdrift flux) is

$$
q=\int_{z_{0}}^{z} u_{\mathrm{S}}(z) c(z) \mathrm{d} z
$$

where $u_{\mathrm{S}}$ is the mean horizontal particle velocity, $c(z)$ is the snowdrift density, and $z_{S}$ is the height of the saltation layer. Many empirical formulae have been developed for the snowdrift transport, $q$, in the two-dimensional case. Iversen (1980) expressed snowdrift-transport rate as a function of frictional velocity

$$
q=c \frac{\rho}{g}\left(u_{\mathrm{f}} / u * t\right) u *{ }^{2}(u *-u * t)
$$

where $\rho$ is the fluid density, $g$ is the acceleration due to gravity, $u_{\mathrm{f}}$ is the snow-particle terminal-fall velocity, and $u *_{t}$ is the threshold value of frictional velocity.

The distribution of snowdrift-transport rate, $q(x)$, at any particular point in time, is computed by applying Equation (9) using the distribution of friction velocity, $u *(x)$.

The constant, $c$, was obtained by reference to the experimental data $\left(c=2.1, \quad u *=0.15 \mathrm{~m} \mathrm{~s}^{-1}\right)$. This value is similar to that used by Schmidt (1982).

\section{COMPUTATION OF DEPOSITION RATES}

In the calculation, snow deposition was assumed to be due to a difference in the snowdrift-transport rate shown by

$$
\frac{\partial h}{\partial t}=-\frac{1}{\rho_{\mathrm{S}}} \frac{\partial q}{\partial x}
$$

where $\rho_{S}$ is the bulk density of snow.

The height increment, $\mathrm{d} h(=(\delta h / \delta t) \Delta t h)$, is added to the height field $h(x, t)$ in order to obtain a new topography, at a time-step interval $\Delta t_{h}$ later, giving the relationship

$$
h\left(x, t+\Delta t_{h}\right)=h(x, t)+\Delta t_{h} \partial h / \partial t(x, t) .
$$

Ishimoto (1981) showed that the slopes for which this relationship applies could not exceed $\alpha_{0}=30^{\circ}$; special treatment is therefore necessary when a slope exceeds $\alpha_{0}=30^{\circ}$. The following is such a special treatment:

If $\alpha_{0}>30^{\circ}$ at the grid point under consideration, the topography is smoothed, and

$$
h_{i}=\frac{1}{m-i+1} \sum_{j=i}^{m} h_{j}
$$

where $m$ is the grid number at the foot of the slope.

\section{RESULTS}

\section{Air flow}

The simulation was continued until a quasi-steady state was reached. The air-flow patterns computed and observed by using a tuft method are shown in Figure $3 a$ and $b$, respectively, they are similar to each other and an especially close match is observed for separation. Figure $4 \mathrm{a}$ and $\mathrm{b}$ show respectively the contours of the computed and observed velocities. The contours are generally similar, but there are a few differences; for example, the computed velocity is a little smaller than that observed on the windward slope and in the section. 


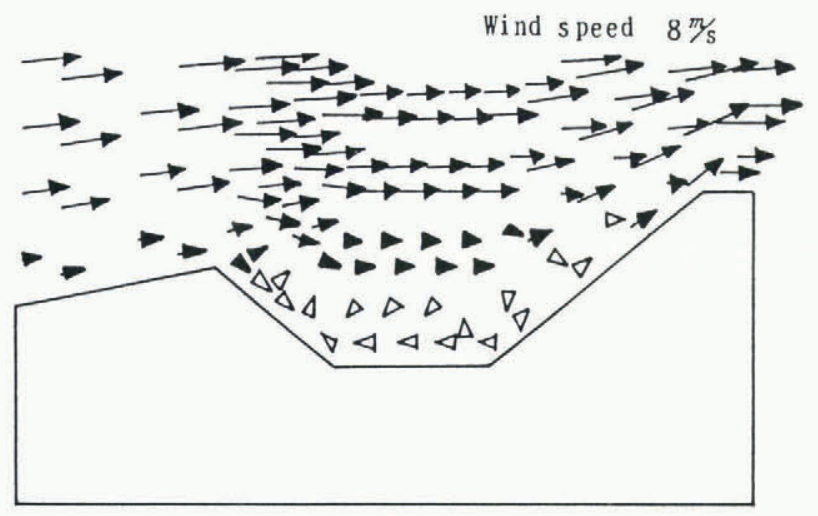

a) Calculation

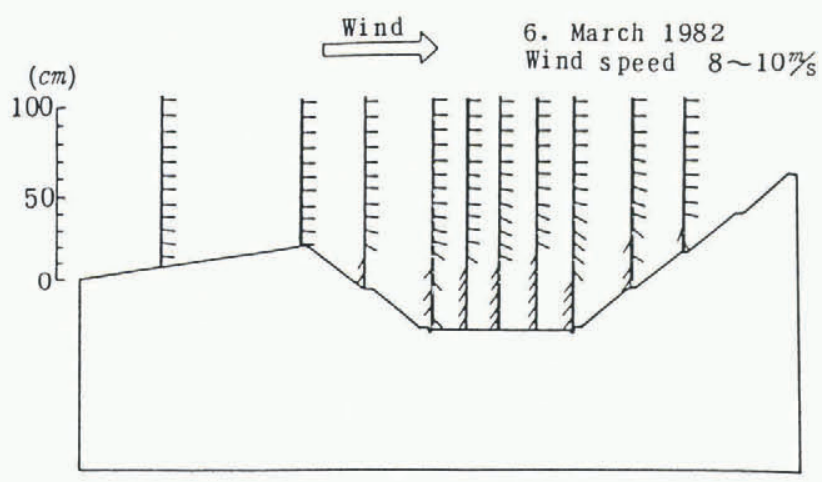

b) Observation by using tuft method

Fig. 3. Comparison of wind-direction fields; (a) calculated, (b) observed by the tuft method, in which 20 short strings were connected with a vertical bar at intervals of $100 \mathrm{~mm}$.

\section{Development of a snowdrift}

The time sequences of computed and observed snowdrifts are shown in Figure 5a and $\mathrm{b}$, respectively. Although their overall characteristics are similar, there was no peak in the centre of the section derived from the calculation corresponding to the presence of an anti-glare screen in the observation site. There were also differences in the total volume of drifted snow. It is suggested that these were caused by wind fluctuations which were not considered in the calculation.

It is clear that at the observation site a great deal of snow transport occurred well down the slope, and out into the base of the trench section. However, the calculation did not predict this, probably because this was due mainly to the gust problem mentioned above. In our calculations, we used mean wind speed for the observation period, which fluctuated between 6 and $8 \mathrm{~m} / \mathrm{s}$ for $10 \mathrm{~min}$ intervals of mean wind-speed measurements. Anderson (1988) reported from his calculations for sand that for decay of deposition rate the length scale increases approximately ten times when the shear velocity increases from 0.3 to $0.6 \mathrm{~m} / \mathrm{s}$. In further simulations, it is planned that wind gust should be taken into account.

\section{CONCLUDING REMARKS}

A method of simulation for the prediction of snowdrifts has been given. The results of the simulation are in reasonable agreement with those observed in a small outdoor model both for snowdrifts and for wind-velocity fields. However, it is clear that more detailed research will be necessary in order to resolve several apparent anomalies in the present work. The method is now being improved by

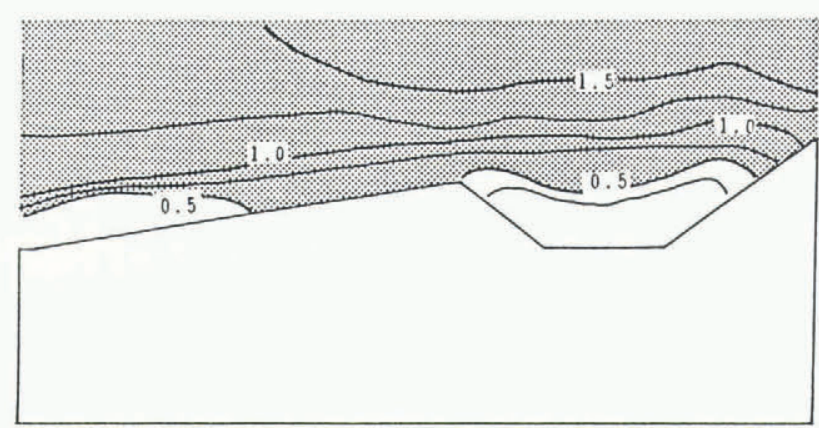

a) Calculation

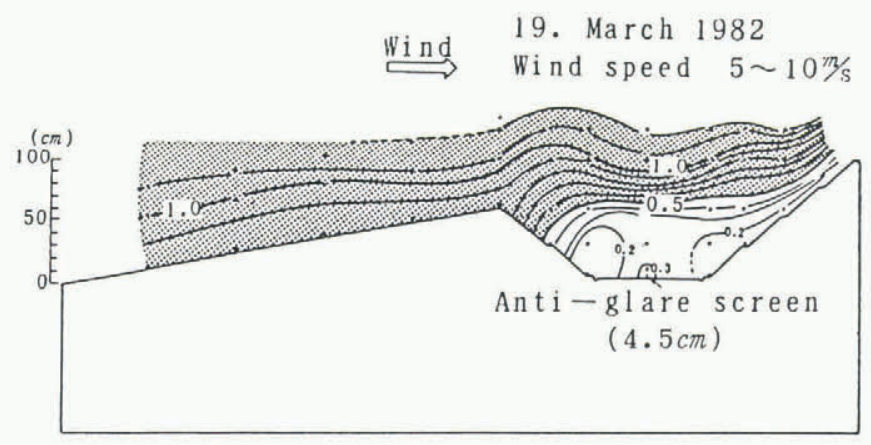

b) Observation

Fig. 4. Comparison of calculated (a), and observed (b), wind-velocity fields. Wind-velocity fields were observed with a hot-wire anemometer and are expressed as a ratio of wind velocity to inflow at a height of $1 \mathrm{~m}$. Contours of wind-velocity ratios are shown at intervals of 0.2 , and screened areas show regions with ratios greater than 0.4 . In (b), dots show the positions of observation points. Wind velocity was not observed simultaneously at every point.

our group in order that it should become a useful technique in the planning of roads, houses, and similar structures.

\section{ACKNOWLEDGEMENT}

We thank Dr N. Maeno and Dr R.S. Anderson for critically reviewing the manuscript of this paper.

\section{REFERENCES}

Anderson, R.S. 1988. The pattern of grainfall deposition in the lee of aeolian dunes. Sedimentology, 35, 175-188.

Anno, Y. 1985. Development of a snowdrift wind tunnel. Cold Reg. Sci. Technol., 10(2), 153-161.

Ishimoto, K., M. Takeuchi, Y. Hukuzawa, and T. Nohara. 1981. Method of protecting roads from blowing snow in a cutting. [In Japanese.] Monthly Report of the Civil Engineering Research Institute, 335, 13.

Irwin, P.A. 1983. Application of snow-simulation model tests to planning and design. Proc. East Snow Conf., 28, $118-130$.

Kobayashi, D. 1972. Studies of snow transport in low-level drifting snow. Contrib. Inst. Low Temp. Sci., Ser. A, 24.

Ohnishi, K. 1986. Analysis of stream. [In Japanese.] Asakura Shoten.

Schmidt, R.A. 1982. Properties of blowing snow. Rev. Geophys. Space Phys., 20(1), 39-44.

Tabler, R.D. and R.L. Jairell. 1980. Studying snowdrifting problem with small-scale models outdoors. Proc. West. Snow Conf., 48, 1-13.

Wipperman, F.K. and G. Gross. 1985. The wind-induced shaping and migration of an isolated dune. A numerical experiment. Boundary Layer Meteorol., 36, 319-334. 

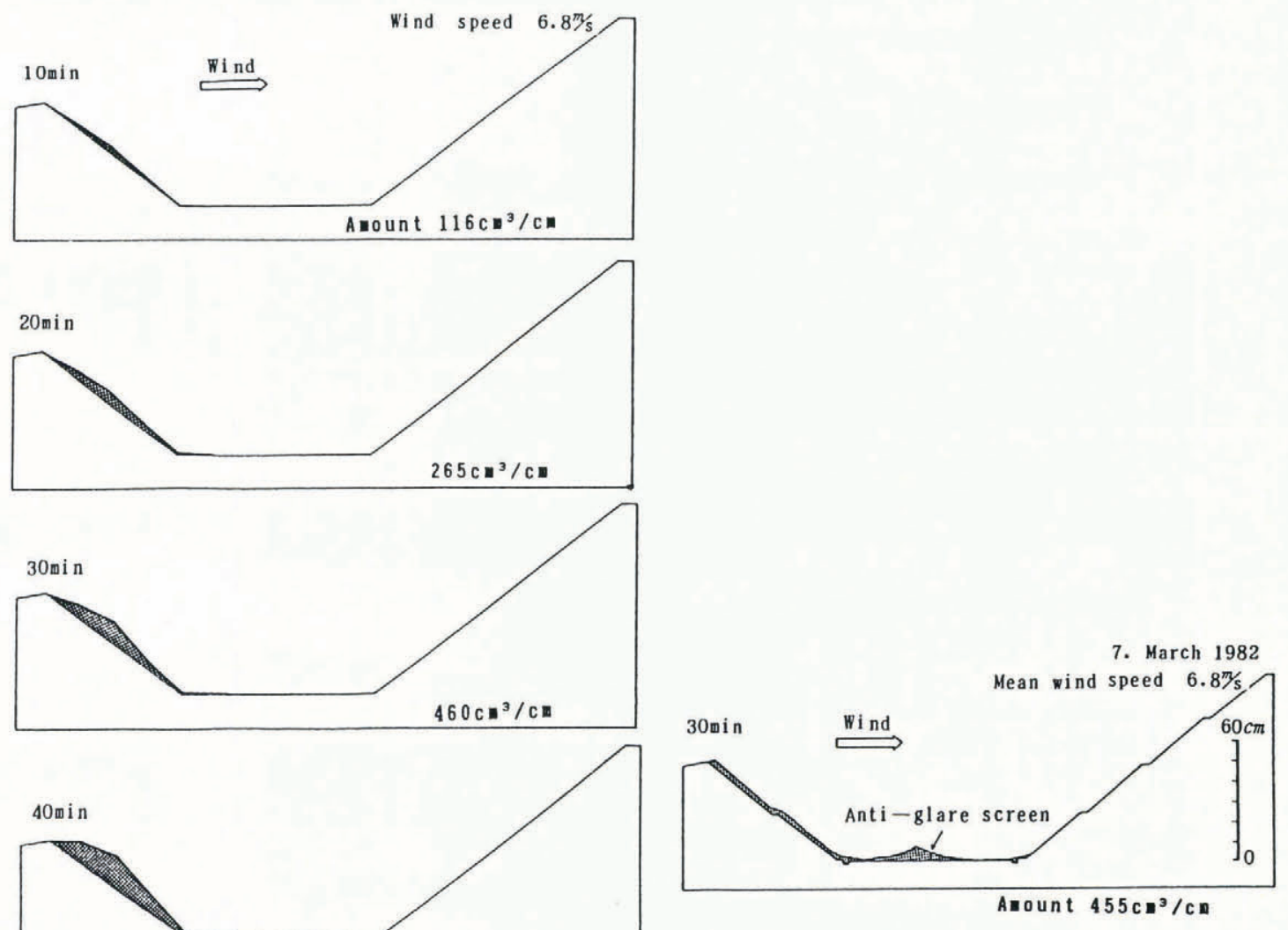

$743 \mathrm{~cm} / \mathrm{cm}$
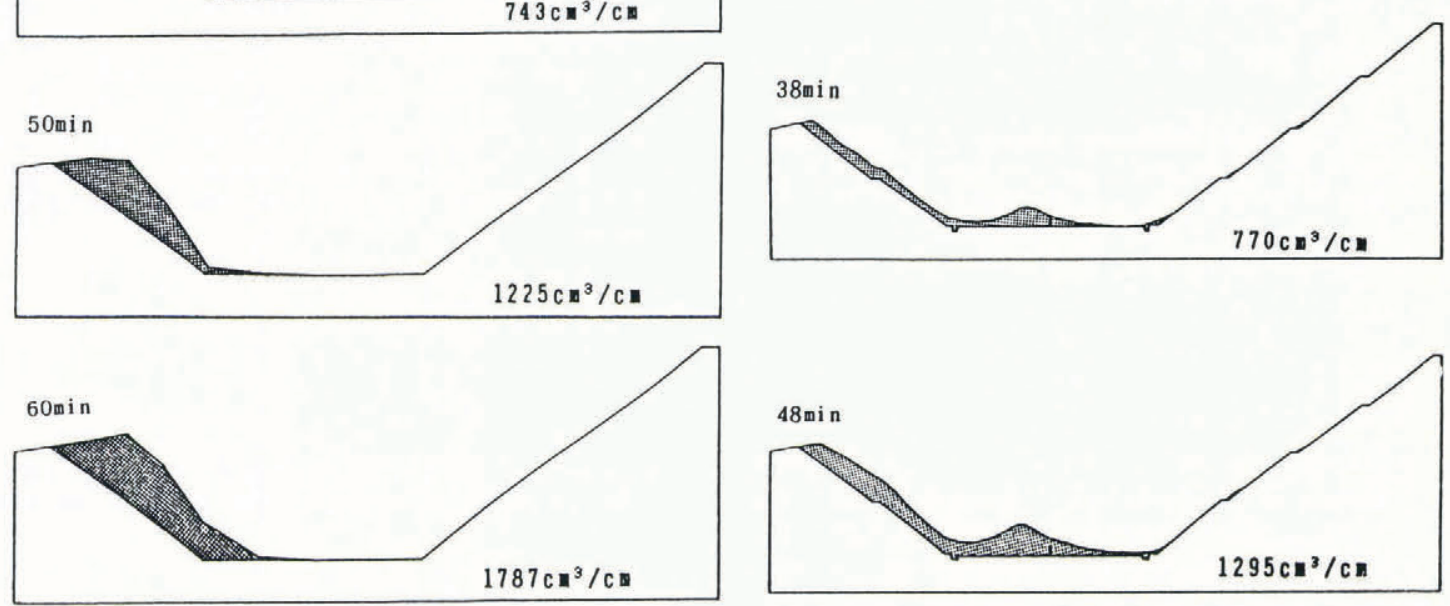

a) Calculation

b) Observation

Fig. 5. Comparison of the calculated (a), and observed (b) snowdrifts. Shaded areas are snowdrifts. 